\title{
DESCENTRALIZAÇÃO DA POLÍTICA AMBIENTAL NO BRASIL
}

\author{
Fernando Paiva Scardua* \\ Maria Augusta Almeida Bursztyn**
}

\begin{abstract}
Resumo: A descentralização, como parte da implementação da Política Nacional de Meio ambiente, tem ocorrido de forma fragmentada, descontínua e seletiva, ao longo das duas últimas década do século XX. Nesse período, os estados e municípios brasileiros experimentaram diferentes graus de descentralização, tornando-se necessárias ações coordenadas pelo governo central. A vulnerabilidade institucional de vários estados e municípios, atrelada ao baixo capital social, são fatores relevantes a serem considerados na formulação de uma política ambiental efetiva.
\end{abstract}

Palavras-chave: políticas públicas, gestão ambiental, política ambiental, descentralização

\section{Introdução}

O tema políticas públicas tornou-se objeto de um intenso debate nas duas últimas décadas do século XX. No âmago do debate se situa uma ambigüidade existencial: por um lado, a crescente complexidade das sociedades, juntamente com uma maior expectativa social no sentido de regulação pública; por outro lado, uma maré liberal passou a representar limitações efetivas à ação estatal. Uma característica evidente do início do século XIX tem sido, nesse sentido, a busca de novas formas de regulação, alternativas à ação imperial do Estado, mas também capaz de superar as evidentes imperfeições do mercado.

\footnotetext{
* Doutor em Desenvolvimento Sustentável, consultor da FAO.

** Doutora em Ciências Ambientais, professora da Universidade de Brasília.

Artigo recebido em 14 ago. 2003; aprovado em 22 set. 2003.
} 
As políticas públicas podem ser implementadas de formas distintas, podendo ser altamente centralizadoras, ou materializadas em parceria com outras instituições e esferas de governo e até mesmo com organizações da sociedade civil organizada. Mas podem também se dar por meio de ações terceirizadas, desconcentradas ou ainda descentralizadas para outras esferas de governo.

A descentralização como estratégia operacional que molda o modus operandi de uma nova concepção de políticas públicas, tem sido associada a mecanismos também inovadores, como a abertura de canais de participação dos atores sociais envolvidos. Como assinala Buarque,

A descentralização é a transferência da autoridade e do poder decisório de instâncias agregadas para unidades espacialmente menores, entre as quais os municípios e as comunidades, conferindo capacidade de decisão e autonomia de gestão para as unidades territoriais de menor amplitude e escala (Buarque, 1999, p. 16).

Silva (1995) e Silva \& Costa (1995) assinalam que os processos de descentralização têm sido caracterizados, em vários países, como um esforço de reforma administrativa do aparato estatal, que são determinados por novas condições econômicas, políticas e sociais mundiais. Neste sentido, os autores enfatizam dois paradigmas nos quais está assentada a descentralização.

O primeiro - hegemônico no plano político-ideológico e constante do receituário de organismos internacionais de promoção do desenvolvimento e de regulação econômico financeira - caminha no sentido da devolução, à sociedade organizada, de recursos e de mecanismo de coordenação e controle ainda nas mãos do Estado, que passam a ser regulados preponderantemente pelo mercado. A descentralização resultante é considerada diferenciadora, seletiva e fragmentada. $\mathrm{O}$ segundo - que se mira em experiências bemsucedidas de países da comunidade européia - enfatiza a reestruturação política, econômico-social e espacial dos Estados-nações, conduzida de forma dinâmica, menos autárquica e mais cooperativa, com a esfera pública concentrando-se nas funções de planejamento estratégico, regulação articulada ao mercado e promoção do desenvolvimento social. A descentralização resultante assume caráter integrador e equalizador. (grifo nosso). 
Kliksberg (2000, p.21), ao enfocar os traços característicos do processo que vem marcando o debate sobre políticas públicas no contexto da América Latina, e que tem encontrado espaço de reflexão na CEPAL, assinala que

a descentralização oferece teoricamente vantagens derivadas de uma provisão de serviços locais que fomentam uma maior responsabilidade e um melhor controle por parte dos usuários e das respectivas comunidades e que podem traduzir-se em uma gestão social melhor. Em vista das disparidades das entradas e disponibilidade de capital humano no interior dos países da região [América Latina], esse repasse de responsabilidade social, pode ter um sério impacto em termos de equiidade territorial.

Uma constatação já pode ser evidenciada, como produto de novas práticas adotadas pelos governos em países com características semelhantes às do Brasil: tem havido uma grande profusão de experiências de descentralização, muitas delas apoiadas ou fomentadas por agências internacionais de desenvolvimento, como o Banco Mundial e o BID. Os resultados já podem ser objeto de análise, com vistas a possíveis correções de rumo. Fica claro que, por meio da transferência de competências, mas não de recursos, e por meio da fragmentação do processo político, afirma-se que a descentralização cumpre a função de adaptar a regulamentação estatal às novas condições de acumulação do capital mundial (liberalismo), dentro de um marco de crise econômica e fiscal. Nessa perspectiva, a descentralização contribui não tanto com o aumento da legitimidade do ordenamento político, mas com a diminuição da presença legitimadora do Estado central, em um sentido instrumental de governabilidade.

Conceitualmente, entende-se por desconcentração o aumento da autonomia do governo central em escritórios regionais. Nesse sentido, a desconcentração transfere algumas ações das sedes de organismos centrais para o interior, preservando a relação hierárquica entre o governo central e o interior (Burki et al., 1999).

Alguns outros conceitos devem ser definidos, como base para o entendimento do tema que é focado no presente artigo. A parceria pode ser tratada como um desmembramento necessário à descentralização, trazendo as mesmas possibilidades, na sua 
utilização. A terceirização de serviços, ora em curso nos estados modernos, é apenas um capítulo do processo de contratação de terceiros que ganhou força em meados do século XX, quando as obras públicas passaram a ser implementadas por terceiros (Pereira, 1998). A publicização $o^{I}$ é a transferência para o setor público não-estatal. $\mathrm{O}$ termo foi criado para distinguir este processo de reforma do processo de privatização.

A descentralização, para ser efetiva, deve contar com a solidariedade e a participação social, que passa necessariamente pelo entendimento da questão da subsidiariedade, que constitui um dos três princípios básicos que norteiam o sistema federativo, juntamente com o da autonomia e o da interdependência.

Montoro (1995, p. 59) define a subsidiariedade como um "princípio baseado no bom senso, em que tudo que puder ser feito no município deve ser feito por ele, o que ele não puder, o Estado vem em auxílio, e o que o Estado não puder fazer a União subsidia”.

Sayago (2000), analisando a crescente importância do discurso da participação como uma nova panacéia que passou a marcar as práticas dos formuladores de políticas públicas, afirma que na realidade não se trata de um novo princípio, mas tão somente de uma nova leitura de experiências anteriores, das quais já se pode ter uma visão crítica das vantagens e limitações. "A participação foi utilizada a primeira vez na década de 1960 , como atributo de processos decisórios ou advocacy planning. A participação foi entendida, então, como o elo que uniria a esfera do indivíduo com a esfera da sociedade" (Sayago, 2000, p.40).

Para Jacobi (2000, p.27), a participação social "se enquadra no processo de redefinição dos setores público e privado, visando redistribuir o poder em favor dos sujeitos sociais que geralmente a ele não têm acesso. Trata-se de pensar o ordenamento de diferenças no contexto do questionamento do papel do Estado enquanto regulador da sociedade". Tem como objetivo principal "facilitar, tornar mais direto e mais cotidiano o contato entre os cidadãos e as diversas instituições do Estado, e possibilitar que estas levem mais em conta os interesses e opiniões daqueles antes de tomar decisões ou de executá-las" (Borja apud Jacobi, 2000, p. 31), minimizando os efeitos/ 
limitações da democracia representativa, via engajamento da sociedade civil na formulação de políticas públicas e no controle das ações governamentais e da coisa pública. Neste sentido, a

participação deve ser entendida como um processo continuado de democratização da vida municipal cujos objetivos são: a) promover iniciativas a partir de programas e campanhas especiais visando ao desenvolvimento de objetivos de interesse coletivo; b) reforçar o tecido associativo e ampliar a capacidade técnica e administrativa das associações; e c) desenvolver a participação na definição de programas e projetos e na gestão dos serviços municipais. (Jacobi, 2000, p. 29).

A participação social é essencial para que ocorra a democracia participativa e representativa. Todavia, o governo deve ser imparcial e intervir no processo de forma a diminuir as distorções econômicas inerentes ao sistema, da maneira mais transparente possível.

A sociedade brasileira, na maioria das vezes, na qualidade de espectadora das ações governamentais, só procura seus direitos no momento em que existe algum fator ou evento que a prejudique ou que lhe traga desconforto. Essa postura - típica de sociedades que possuem baixo capital social - ensejam medidas de incentivo por parte do governo central, para que a sociedade venha a participar dos esforços de melhoria da qualidade de vida, que começam no âmbito local.

A descentralização na esfera das políticas ambientais é o objeto deste artigo. O foco central são os elementos e as condições que caracterizam o processo de gestão ambiental no Brasil. Uma breve contextualização do processo de descentralização das políticas publicas, em geral, é necessária como referência.

\section{A descentralização das políticas públicas no Brasil}

Falar de descentralização das políticas públicas brasileiras, nos remete ao entendimento do quadro político-social vivenciado pelo Brasil nos últimos 40 anos do século XX (1960-2000), mais precisamente, ao entendimento de como se processou a formulação e transformação do novo estado brasileiro, sua distribuição territorial 
(fragmentação), a estruturação política (bipartidária-pluri ou multipartidária), financeira (centralizada-descentralizada) e institucional (centralizada-desconcentrada).

Vários autores têm apontado o tipo de federalismo e de relações intergovernamentais existentes no Brasil como obstáculos a alterações em diferentes áreas, incluindo a descentralização das políticas sociais, tais como: saúde, habitação e educação; setores de infra-estrutura, como: transporte e energia elétrica; finanças públicas e estrutura fundiária; e no sistema político (Abrucio, 1994). Muitas vezes, esses obstáculos emergem historicamente do processo de transição democrática.

Ferreira (1995) observa períodos em que houve maiores ou menores avanços na descentralização das políticas públicas, a saber:

I. Na República Velha (1889 a 1930), caracterizada pela implantação do sistema federativo de governo, existia um controle da máquina governamental pela oligarquia rural;

II. O período da Ditadura Vargas (1930 a 1945), tem a centralização na pessoa do presidente e uma política voltada para um projeto nacional de desenvolvimento urbano, industrial e nacionalista. Nesse período, o governo amplia seu poder de influência nas cidades e dissolve as representações políticas;

III. Durante o período democrático (1945 a 1964), ocorre a restauração do sistema federativo descentralizador, com a reorganização dos partidos políticos e o sistema de representações, porém sem uma clara política nacional de descentralização;

IV. No período de 1964 a 1985, durante a ditadura militar, observamos o retorno da centralização do poder nas mãos dos militares, técnicos burocratas e da burguesia industrial. Os governos locais são meros gestores das políticas centrais, por meio da nomeação de interventores em cidades de áreas de fronteira, estâncias hidrominerais, capitais e até de governadores; 
V. A partir de 1985, inicia-se um novo processo de revisão do papel do Estado brasileiro, no qual as teorias de Estado mínimo e neoliberal frutificaram e ganharam corpo.

Com a promulgação da Constituição da República Federativa do Brasil de 1988 é que o poder local ganha um papel central dentro do contexto federativo. Não obstante, a divisão entre direitos e deveres, prevista na Carta Magna, não foi suficientemente detalhada, aguardando emendas constitucionais para ser efetivada. Nesse ínterim, um vácuo institucional e administrativo vem reinando em vários setores, como o educacional, de saúde, de segurança, tributário e ambiental.

No campo das políticas públicas federais, a descentralização apareceu primeiramente na área de saúde, em meados da década de 1980. Em 1983 foram assinados com Estados e municípios os primeiros convênios das Ações Integradas de Saúde (AIS) e, em 1987, com os Estados, os primeiros convênios do Sistema Unificado e Descentralizado de Saúde (SUDS). A estratégia adotada consistiu em implantar a descentralização de forma gradativa, associando-a à criação de espaços institucionais de participação social através de Conselhos de Saúde - previstos em todas as esferas, embora não necessariamente com caráter deliberativo. Em 1988, tem início a implantação do Sistema Único de Saúde (SUS), concebido como um sistema descentralizado e com comando único em cada esfera de poder.

O setor de educação, por sua vez, não se descentralizou como o setor de saúde. A Constituição de 1988 previu tão-somente que os diferentes níveis de poder organizem seus respectivos sistemas de ensino "em regime de colaboração", estabelecendo que os municípios atuem prioritariamente na rede pré-escolar e no ensino fundamental. De maneira geral, os Estados aparecem como os principais responsáveis pelo ensino fundamental e de nível médio, participando, também, em alguns casos, do ensino universitário; os municípios respondem pela educação infantil, enquanto o governo federal é o principal responsável pelo ensino superior, envolvendo-se, ainda, com a construção de escolas para o ensino fundamental e o desempenho das funções de apoio, como a merenda escolar e os livros didáticos. 
A assistência social foi a que mudou menos do ponto de vista da redistribuição efetiva de competências e atribuições entre instâncias de governo. Em 1986, a comissão de apoio à reestruturação da assistência social, criada pelo governo federal, elaborou um diagnóstico com os principais problemas da assistência social no país: concepção assistencialista e utilização clientelista das ações, insuficiência de recursos, fragmentação institucional, superposição de ações realizadas pelas três instâncias de governo, excessiva centralização financeira e político-administrativa das políticas e programas federais, e baixa qualidade do atendimento. Tal diagnóstico subsidiou a constituinte de 1988, sendo que algumas de suas proposições foram incorporadas no texto constitucional. Assim, a assistência à seguridade social foi tratada como direito indispensável para garantir a cidadania; foi criada a renda mínima vitalícia para o idoso, carentes e deficientes físicos; foi estabelecida a gestão políticoadministrativa participativa; foi preconizada a municipalização da assistência social; foram definidas, com mais clareza, as formas e fontes de financiamentos, destinando ao setor $10 \%$ dos recursos do orçamento da seguridade social (OSS), além de recursos ordinários do tesouro e dos orçamentos de Estados e municípios. Tais preceitos constitucionais foram materializados na Lei Orgânica da Seguridade Social (LOAS). As ações descentralizadoras não são radicais e nem isentas de ambigüidades, sendo que tais mudanças foram mais de cunho de definição das funções mais normativas e reguladoras da União do que executivas.

Já no setor de habitação ocorreu o inverso: o setor foi alvo de mudanças dramáticas no desempenho efetivo de papéis pelas diferentes instâncias de governo. Tais mudanças foram em função da desarticulação progressiva da instância federal, via mudanças institucionais e, principalmente, devido à redução drástica dos recursos que alimentaram a política habitacional centralizada por mais de 20 anos. As mudanças institucionais ocorreram em função da mudança do Sistema Financeiro Habitacional (SFH) e da extinção do Banco Nacional de Habitação (BNH). Tais modificações resultaram na ausência de uma agência ou órgão regulador de uma política nacional de habitação, que vem sendo substituída por bancos privados, pela Caixa Econômica Federal - gestora do Fundo de Garantia do Tempo 
de Serviço (FGTS)-, por empresários do setor de comercialização de imóveis (SECOVI) e secretários estaduais e municipais gestores de programas habitacionais para baixa renda.

Desta forma, o setor de habitação, ora centralizado, passa a ser uma iniciativa dos governos estaduais e municipais, que sofrem de descontinuidade e assumem diversas formas no território nacional.

Kliksberg (2000) aponta alguns riscos da descentralização. Os municípios apresentam grandes diferenças entre si. Desta forma, nos processos de transferência de recursos, se não forem tomadas medidas para se fazer um re-equilíbrio regional, as vantagens da descentralização podem se tornar piores que a situação anterior. Logo, o poder central tem que garantir condições de eqüidade. Delegar atribuições impositivas pode ter resultados muito distintos segundo as capacidades contributivas reais dos diversos tipos de municípios. Outro risco é devido aos níveis de polarização social existente no interior dos Estados regionais e nos municípios. Em numerosos casos, as oligarquias locais pequenas controlam o funcionamento da sociedade local, sendo mais fácil haver cooptação pelas minorias para a execução de políticas sociais de seu interesse. Não basta o interesse de descentralização por parte do governo central, sem um maior envolvimento da sociedade civil organizada. E mesmo na existência de tal instância deliberativa, ela deve ser isenta e capacitada para atender aos anseios da comunidade em geral, e não aos interesses de determinados grupos ou do poder local.

A participação social é outro ponto fundamental para a implantação da descentralização, de forma a contribuir para a democratização do país. Entretanto, a simples participação não representa um ganho para a melhoria da gestão pública porque a representação social não é suficiente para a garantia da definição e monitoramento das ações do poder público. Por isso ela deve estar presente em todo processo de tomada de decisão, principalmente naquele referente à fiscalização das ações empreendidas.

A participação social no Brasil remete-nos às praticas clientelistas e continuístas do coronelismo (Sayago, 2000) que, muitas vezes - para não dizer a maioria das vezes - não são levadas em 
consideração na formulação de políticas e programas governamentais, pois partem da premissa que a participação é a mola impulsionadora do desenvolvimento social. Disso pode ocorrer que as elites locais, que tradicionalmente detêm o poder político, encontram nesse mecanismo uma oportunidade de reciclar suas práticas, revigorando e atualizando suas bases de legitimação, como um novo tipo de coronelismo.

A descentralização pode levar ao paroquialismo, ao conformismo e ao exercício do poder oligárquico por elites locais, podendo oferecer riscos como o declínio da qualidade dos serviços prestados. Como assinala Jacobi (2000, p. 34) na visão dos mais "céticos onde prevalece a idéia de que a descentralização apenas transfere poder das elites nacionais para as elites locais, e que o maior acesso destas últimas aos recursos públicos apenas aumenta as oportunidades de corrupção". Não é possível generalizar para todos os locais, pois pode haver locais em que as qualidades dos serviços pioram e outros em que elas melhoram.

Para muitos de seus partidários, a descentralização constitui um instrumento propício para democratizar os processos sociais, aumentar a participação popular e reduzir a injustiça social nas comunidades locais envolvidas. Porém, ainda não foi demonstrado que as políticas de descentralização permitem cumprir com os objetivos de reestruturar as relações de poder, democratizar os processos sociais, aumentar a participação da cidadania e/ou reduzir as desigualdades inter e intralocais (Matos, 1989).

\section{Descentralização da política ambiental brasileira}

A política ambiental pode ser definida como um conjunto de atividades e procedimentos com os diferentes níveis de competências e organizações, supranacionais, do Estado (Administração Central, Autônoma e Local), e as empresas e organizações não-governamentais, que pretendem alcançar determinados fins de proteção do meio ambiente e conservação da natureza (Fernandez-Vítora, 1997).

Antes da promulgação da Constituição Brasileira de 1988, a Lei $n^{\circ}$ 6.938/81, que instituiu a Política Nacional de Meio Ambiente 
(PNMA), já previa um sistema descentralizado de gestão ambiental no Brasil, por meio de um Sistema Nacional de Meio Ambiente (SISNAMA), constituído por um órgão superior, um órgão consultivo deliberativo, um órgão central, um órgão executor, órgãos seccionais e órgãos locais. A forma, como e quando deveriam ser feitas tais atividades não haviam sido discutidos com os estados e muito menos com os municípios, estes últimos, alvos das ações previstas no SISNAMA.

A discussão das questões referentes à centralização versus descentralização da política ambiental brasileira - é fruto de intenso processo de desenvolvimento da sociedade brasileira, que atingiu um amadurecimento refletido na atual Constituição, avançada sob o ponto de vista de meio ambiente, porém com grandes desafios para sua implementação.

Foi um longo percurso do ponto de vista constitucional, como pode ser observado na análise elaborada por Souza (1992) das constituições brasileiras, no que se refere à área ambiental:

I. A Constituição de 1934 apresentava, pela primeira vez, a competência privativa da União para legislar sobre a riqueza do subsolo, mineração, metalurgia, águas, energia hidrelétrica, florestas, caça e pesca e sua exploração, embora não excluísse a competência estadual para legislar supletivamente sobre essas matérias.

II. Já a Constituição de 1937 mantém a competência privativa da União para legislar sobre minas, energia hidráulica, águas, florestas, caça e pesca e a competência supletiva dos Estados. Nela, também aparece o primeiro elemento ambientalista para o interior das normas constitucionais quando, na alínea " $e$ " do art. 18, estabelece que os Estados, independentemente de autorização, podem legislar sobre medidas de polícia para a proteção das plantas e dos rebanhos contra moléstias ou agentes nocivos, desde que não contrariem ou diminuam as exigências federais. Também inova ao estabelecer que os monumentos históricos, artísticos e naturais, como as paisagens e os locais particularmente dotados pela natureza gozam da proteção 
e dos cuidados especiais da Nação, dos Estados e dos municípios.

III. A Constituição de 1946 reproduz - com adaptações e atualizações - a constituição de 1934, mantendo a competência da União e dos Estados para legislar sobre riquezas do subsolo, mineração, metalurgia, águas, energia elétrica, florestas, caça e pesca, permitindo a competência supletiva do estado.

IV. A Constituição de 1967-69 explicita que os Estados têm competência legislativa supletiva sobre materiais como jazidas, minas e outros recursos minerais, floresta, caça e a pesca, águas e energia, acrescentando, neste último setor, as energias térmica e nuclear. Nesta Constituição aparece mais um dispositivo inovador no qual a questão ecológica aparece de forma expressa (art. 172), determinando que a lei regulará, mediante prévio levantamento ecológico, o aproveitamento agrícola de terras sujeitas a intempéries e calamidades.

V. Já a atual Constituição traz, pela primeira vez explicitamente, a preocupação com o meio ambiente. Nela é criada uma série de dispositivos (arts. 225, 231 e 232 e arts. 196 a 204) que tratam da questão ambiental e da qualidade de vida.

A Constituição Federal do Brasil, de 1988, trouxe avanços em vários aspectos do direito, tendo elevado os municípios à condição de unidade federada e estabelecido a repartição de competências e a previsão do direito do meio ambiente. Esse novo status trouxe ao município alguns novos traços de ordem política e jurídica, notadamente quanto à sua autonomia, à sua capacidade de autoorganização e a seu governo. Isso aparece implícito nos arts. 23, 24, 30 e 225 da Constituição Federal.

A elevação do município à categoria de ente federativo trouxe mais obrigações e competências para eles; ficaram, porém, desprovidos de capacidade institucional, administrativa e financeira para cumprir essas novas atribuições. 
Desde o início do processo de elaboração da PNMA tem havido uma atitude governamental voltada à descentralização, ou seja, ao repasse de atribuições e responsabilidades em matéria de política e gestão ambiental às Unidades da Federação. Segundo Paulo Nogueira Neto, ${ }^{2}$

$o$ anteprojeto de lei de meio ambiente foi elaborado pelo MINTER e encaminhado pelo governo para a Câmara onde foi montada uma comissão mista para avaliá-la. Essa comissão trabalhou em conjunto, governo e oposição, no sentido de analisá-la, tendo sido aprovada por voto de liderança.

O Ministério do Interior (MINTER) não se opunha à descentralização da gestão ambiental, tendo em vista que ele próprio já executava ações descentralizadas, por atuar por regiões (Norte, Nordeste, entre outras, via Fundos Constitucionais). A Secretaria Especial de Meio Ambiente (SEMA), por sua vez, tinha como objetivo descentralizar para os Estados as ações ambientais, pois já havia percebido que a atuação local era a mais efetiva no trato da questão ambiental. Assim, a concepção da própria lei já apresentava o espírito extremamente descentralizado.

Ao longo dos 21 anos da implementação da PNMA, o empenho do governo federal para descentralizar suas ações tem se mostrado tímido, e é marcado por períodos de avanços e retrocessos. Nos primeiros anos de sua implementação, observou-se uma série de posturas por parte do órgão central, no sentido de descentralizar ações, mesmo no período de regime fechado. Apesar do momento especial que o Brasil enfrentava, várias ações foram empreendidas para criar estruturas estaduais de meio ambiente. Ainda na década de 1980, a política ambiental era vista meramente como uma limitação ao modelo de desenvolvimento do país, postura presente em alguns segmentos e setores do governo e da iniciativa privada, apesar do discurso ecológico. Já na década de 1990, várias mudanças foram se processando na esfera federal, o que permitiu que ações induzidas por parte do governo central fossem empreendidas.

Tais ações ganharam formato, ainda que de forma incipiente e desordenada, por meio de Programas do Ministério do Meio Ambiente (Programa Nacional do Meio Ambiente - PNMA I ${ }^{3} \mathrm{e} \mathrm{II}^{4}$ - e Programa 
Piloto para a Proteção das Florestas Tropicais do Brasil - $\mathrm{PPG}^{5}$ ). Em seu esboço estão previstas algumas ações de fortalecimento institucional, capacitando inicialmente os estados a assumirem algumas atribuições do governo central e, posteriormente, alguns municípios.

No caso dos Estados brasileiros, desde 1996, todas as Unidades da Federação possuem políticas ambientais estaduais e instituições responsáveis pela sua implementação. O gráfico 1 mostra a evolução desse processo.

\section{Gráfico 1 - Evolução das políticas ambientais estaduais}

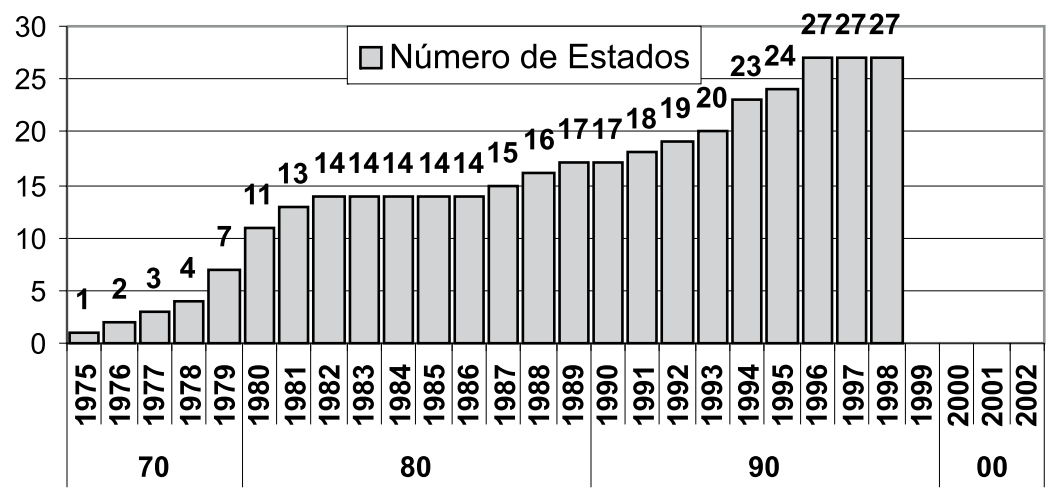

Decádas/ Anos

Dado que a descentralização envolve diferentes esferas de governo e que, em última instância, o ente federado tem a prerrogativa de querer ou não assumir outras atribuições além daquelas já designadas na Constituição Federal, a implementação do SISNAMA tem sofrido atrasos na sua implantação. Isto porque as diferentes interpretações acerca da necessidade ou não de se ter uma lei complementar para regulamentar alguns artigos da $\mathrm{CF}$ brasileira ainda são apontadas por alguns juristas como um entrave para que a descentralização da gestão ambiental brasileira venha a ocorrer de fato. 
A descentralização da questão ambiental ainda necessita de acordos individuais entre União e Estados, via convênios, contratos, acordos de cooperação ou pactos federativos.

Normalmente, o objetivo geral desses pactos é a cooperação técnica e administrativa, das competências constitucionais de proteção do meio ambiente e dos recursos naturais renováveis, promovendo, assim, a interação política e institucional da gestão descentralizada compartilhada. O pacto federativo tem por finalidade a descentralização das ações da esfera federal para os Estados. Tais pactos guardam peculiaridades entre si, pois levam em conta o status institucional e instrumental existente em cada unidade da federação. Essas peculiaridades é que permitem que se avance na definição de competências constitucionais, o que não significa que o órgão federal não continua sendo responsável pela gestão dos recursos naturais renováveis, objeto de repasse de atribuições.

Observa-se que, dadas as diversidades culturais, econômicas e ambientais dos Estados e municípios, o grau de centralidade do governo federal é necessário para a manutenção e a articulação do SISNAMA, porém com ações voltadas para as peculiaridades locais. Os Sistemas Estaduais de Meio Ambiente (SISEMAs) devem encontrar caminhos próprios para sua estruturação, procurando, porém, incorporar os representantes do poder público municipal, além da participação efetiva da sociedade civil organizada. Devido aos diferentes formatos e modelos de gestão existentes, é difícil afirmar qual o melhor modelo em função das peculiaridades locais.

De maneira geral, o que podemos observar é que o fortalecimento das instituições encarregadas de zelar pelo cumprimento do PNMA, nos Estados, tem permitido que elas empreendam ações de descentralização para os municípios. Entretanto, quanto ao ganho ambiental ou da melhoria da qualidade de vida para a população ainda é prematuro fazer qualquer afirmativa, tendo em vista que o processo de descentralização está apenas começando.

Apesar das vantagens da participação social estar prevista no PNMA, sua representatividade não condiz com a participação que auxiliaria na construção do capital social descrito por Putnam (1996). 
Isto porque prevalece no pensamento de muitos ambientalistas brasileiros que os únicos interlocutores capazes de representar a sociedade civil são as ONGs ambientalistas, apesar de não terem sido em nenhum momento escolhidas pelos cidadãos como seus reais representantes nestes fóruns. Além disso, a questão ambiental é interdisciplinar, o que a torna fórum de debate e participação de várias organizações representativas e participativas da sociedade civil e não só da ambientalista.

No âmbito federal e estadual, a maioria dos Conselhos Nacional e Estadual são paritários e deliberativos - alguns deles têm maior representação de outros segmentos que não o poder público. Apesar da aparente paridade, sua representatividade ainda é questionável, porque muitos dos representantes da população, nesses conselhos, não a representam verdadeiramente.

Outro ponto ainda pouco esclarecido diz respeito à proliferação de organismos colegiados em nível local - voltados a diferentes esferas de decisão pública - que poderiam fragilizar a representatividade (muitas instâncias representativas para poucas representações, e com pouca representatividade) na tomada de decisões. Isto ocorre porque boa parte dos municípios brasileiros, ou seja, $24,15 \%$, possuem menos de 5.000 habitantes. Por força de lei e independentemente de seu tamanho ou população, devem apresentar vários conselhos para diferentes políticas setoriais. Por ser o contingente populacional baixo, da mesma forma que o nível de escolaridade da população brasileira, muitos representantes de um conselho se fazem presentes em vários outros, o que pode comprometer a governança e o controle social.

A baixa presença de municípios que contam com algum órgão para tratar de meio ambiente $(11,7 \%)$, aliada ao baixo número de Conselhos Municipais de Meio Ambiente (21,37\%) são indicativos de que o meio ambiente ainda não é prioridade, ou ainda não representa um problema para os municípios brasileiros (Scardua, 2003).

A própria participação dos municípios nos órgãos colegiados estaduais é precária - em poucos Estados está prevista sua participação. Este fator, também, pode estar contribuindo para a baixa disseminação das práticas ambientais no âmbito local. 
As práticas clientelistas e coronelistas, ligadas a questões políticas locais, poderão influenciar a forma de atuação dos órgãos municipais de meio ambiente, possibilitando maior desagregação e gerando externalidades negativas para a área ambiental. Caso o processo de descentralização não seja tocado de forma articulada com a participação ativa da população e de órgãos de controle social, como o Ministério Público, tais práticas não poderão ser vencidas.

Verificamos que, à medida que os instrumentos de gestão ambiental federal vão sendo implementados, os Estados tendem a seguir a diretriz federal em graus diferenciados, implementando, assim, ações semelhantes que podem ser agilizadas pela indução de programas federais. No tocante à descentralização para os municípios, essas práticas ainda não encontram a mesma facilidade de ocorrer, muitas vezes por falta de capacidade institucional e participação social.

Deixando de lado os méritos da legislação ambiental que ainda hoje se encontra atualizada, em vários aspectos, há a obrigação de se rever os métodos de participação e representação popular e de proceder a uma revisão do próprio SISNAMA. O descompasso na implementação da gestão ambiental tem gerado passivos ambientais e, até o presente momento, não se tem uma magnitude ou amplitude de seu custo e significado para a sociedade.

A capacidade de o governo federal induzir e produzir mudanças em todo o sistema é desejável e deve ser dirigida para programas específicos, de forma que haja maior objetividade nas ações empreendidas. A capacidade de coordenação dos governos federal e estadual deve ser prevista e necessária, pois, em nível local, os dispositivos de controle social estão nas mãos dos governantes que, muitas vezes, vão no sentido contrário das ações emanadas pela esfera de poder superior. A governabilidade local deve ser contrabalançada por mecanismos de governança que permitam ao sistema diminuir a vulnerabilidade política que é mais premente diante de interesses econômicos, o que poderia ocasionar retrocessos e até distorções na política ambiental local. Isto porque, as elites locais no exercício do poder tendem, algumas vezes, ao paternalismo e ao desenvolvimento de práticas clientelistas, comprometendo a qualidade ambiental. 
Para evitar ou minimizar tais posturas, a participação social deve ser exercida e construída em várias esferas decisórias, para que não se permita prática de cooptação do governante sobre os fóruns de deliberação.

Alguns fatores também têm contribuído para que a descentralização das políticas e instrumentos ambientais para o nível local se processe de forma descontínua no tempo e no espaço. São eles: falta de técnicos nos órgãos estaduais e municipais de meio ambiente; falta de capacitação e treinamento; salários defasados, quando comparados aos praticados pela iniciativa privada; instituições despreparadas para assumir atividades ambientais; carência de recursos financeiros e de infra-estrutura; ausência de instrumentos de gestão ambiental ou instrumentos ultrapassados, dentre outros.

Esses fatores podem ser apontados como sendo um entrave para a institucionalização de fato da gestão ambiental nos municípios. Porém, de forma alguma significam a impossibilidade de atenderem a essa questão, tendo em vista que a própria $\mathrm{CF}$ estabelece que incumbe ao poder público, em todos os níveis, e à coletividade o dever de defender e preservar o meio ambiente para as presentes e futuras gerações.

Os obstáculos existentes para a descentralização da gestão ambiental encontram-se muito mais ligados à cultura dos órgãos centrais - que possuem uma visão centralizadora da forma de atuação, herança do modelo patrimonialista ainda hoje presente em nossa sociedade - do que ao interesse ou não de assumir essa atribuição, além da ausência ou insuficiência de capacidades institucionais, infraestruturais e participação social nos municípios.

A Agenda $21^{6}$ brasileira estabeleceu algumas ações e recomendações para a prática da boa governança e ética para a promoção da sustentabilidade, explícita em seu objetivo 17 descentralização e o pacto federativo: parcerias, consórcios e o poder local. São elas:

I. Fortalecer o federalismo cooperativo e definir as competências entre o Governo Federal, os Estados e os 
municípios, levando em conta o seu tamanho, renda e condições institucionais na configuração espacial brasileira. Elaborar a lei complementar para o artigo 23 da Constituição Federal, que regula o tema.

II. Instituir o princípio de subsidiariedade que determina prioridade para ações de interesse da sociedade civil e, pela ordem, a ação municipal, estadual e federal quando o ente situado em nível espacial inferior não for capaz de exercer suas funções, adequadamente.

III. Regulamentar o artigo 241 da Constituição Federal para fortalecer a cooperação intermunicipal, por meio de estímulo aos consórcios que integram as microrregiões, possibilitando o desenvolvimento de planos de desenvolvimento sustentável, que identifiquem a sua vocação produtiva, atentos à integridade de seus recursos naturais e às exigências do meio ambiente urbano.

IV. Capacitar lideranças sociais para o desenvolvimento sustentável e preparar o terceiro setor para uma atuação mais informativa tecnicamente e isenta politicamente no quadro municipal brasileiro.

V. Capacitar e racionalizar as competências e a ação dos conselhos, integrando suas áreas de competência para a otimização de recursos humanos em nível local.

VI.Aperfeiçoar os mecanismos de controle social, transferência e o acompanhamento dos compromissos públicos assumidos pelos governos (Agenda 21 Brasileira, 2002, p. 81).

Camargo (2002, p.162) enfatiza que a Agenda 21 Brasileira tem o "compromisso de mudar os padrões de governabilidade e de governança, estabelecendo um novo equilíbrio entre sociedade e Estado", baseado no princípio de participação e no processo de descentralização. 


\section{Considerações finais}

A descentralização, entendida como a transferência de autoridade e de poder decisório para instâncias subnacionais, é um dos princípios constantes na Constituição Federal do Brasil de 1988. Esta apresenta uma característica inovadora, ao contemplar mecanismos da democracia participativa, complementares à democracia representativa, no sentido de fortalecer o controle social e a descentralização. Entretanto, isto ainda não ocorreu em nível satisfatório e efetivo.

Nos últimos anos, o processo de descentralização das políticas públicas, nos campos social, econômico e financeiro, processou-se de forma diferenciada nas diversas áreas. Ações empreendidas no campo social não puderam superar algumas práticas clientelistas e paternalistas existentes no Brasil, como assinala Jacobi (2000), apesar de ser um processo irreversível e necessário para atingir a efetividade pretendida pela descentralização.

No campo da gestão ambiental, a descentralização tem sido uma meta perseguida nos últimos 10 anos do século $\mathrm{XX}$ pelo governo federal. Entretanto, os resultados obtidos até o presente momento nos permitem afirmar que não existe um modelo único de ação a ser esboçado para todo o espaço territorial brasileiro pelo governo federal, tendo em vista que as diferenças sociais, econômicas, políticas e culturais podem explicar os diferentes sucessos e insucessos verificados pelos modelos existentes e postos em prática por algumas unidades da federação (por exemplo: Bahia, Rio Grande do Sul e Pernambuco).

Apesar da Política Nacional de Meio Ambiente ter nascido descentralizada, o que ocorreu foi uma ausência de instrumentos operacionais para que fosse realizada uma gestão ambiental de forma adequada. A falta de capacidade institucional, por falta de recursos humanos (quali/quantitativamente) levou à instabilidade dos órgãos ambientais que, no bojo das mudanças políticas, também contribuíram para a desestabilização do sistema ambiental.

Ao longo dos anos, o que se pôde perceber foram ações esparsas e desestruturadas, na tentativa de estruturar e fortalecer o Ministério 
do Meio Ambiente, o IBAMA e os órgãos seccionais de meio ambiente, por meio de alguns programas desenvolvidos pelo MMA.

Podemos observar que a contribuição efetiva do processo de descentralização para a implementação da PNMA ainda está aquém do necessário para que haja uma melhoria da qualidade de vida da população brasileira. Os desafios que se apresentam dependem da forma como serão implementadas as ações necessárias à sua efetividade. Nesse processo a capacidade institucional deverá ser objeto de ações especificas e contínuas, aliadas à maior participação social na tomada das decisões.

As experiências brasileiras recentes de descentralização de políticas públicas não permitem vislumbrar, até o momento atual, uma ruptura com o padrão histórico de "captura" do Estado, no nível local, por práticas tradicionais que marcam a vida política nacional desde os primórdios da colônia. Da mesma forma que as mais variadas fisionomias do coronelismo - versão brasileira do patrimonialismo sempre encontraram espaço para usufruir, de facto, das benesses providas pelo poder central, não há indícios convincentes de que a velha cultura política tenha sido substancialmente revertida. É nesse sentido que o atual esforço de descentralização pode estar sendo tão somente mais um episódio de uma velha prática. Em outras palavras, a democracia participativa pode estar sendo capturada pela tradição, num sentido perverso.

\section{Notas}

1 Vale assinalar que, no Brasil, o termo "publicização" foi adotado na reforma administrativa promovida pelo governo FHC, com o sentido de transferência de responsabilidades públicas a entes não-governamentais, como as OS (organizações sociais). Trata-se - é preciso assinalar - de uma expressão enganosa; mais apropriado seria "despublicização".

2 Paulo Nogueira Neto, ex-Secretário da SEMA, em entrevista realizada no dia 12 jun. 2002.

3 Programa Nacional do Meio Ambiente (PNMA) - um programa elaborado pelo governo brasileiro, por meio de um acordo de empréstimo no valor de US\$166,4 milhões de dólares (financiados pelo BIRD), tendo como finalidade fortalecer o Estado brasileiro em todos os níveis de governo na 
gestão ambiental. O programa teve início em 1991, tendo sido finalizado em 1997, tendo sido estruturado em quatro componentes (Unidades de Conservação, Proteção de Ecossistemas, Fortalecimento Institucional e Projetos de Execução Descentralizada, este último criado após a avaliação de meio termo do Programa).

4 O Programa Nacional do Meio Ambiente II - PNMA II -, objeto de Acordo de Empréstimo entre o governo brasileiro e o Banco Mundial, está direcionado para o aperfeiçoamento do processo de gestão ambiental no País, nos três níveis de governo. O PNMA II está estruturado nos seguintes componentes e subcomponentes: um componente de Desenvolvimento Institucional com quatro temas: Licenciamento Ambiental; Monitoramento da Qualidade da Água; Gerenciamento Costeiro; e Gestão Integrada de Ativos Ambientais; e um componente de Coordenação e Articulação.

5 Programa Piloto para a Proteção das Florestas Tropicais no Brasil (PPG7) - Programa direcionado preferencialmente para a Região Amazônica e Mata Atlântica, que envolvem recursos da ordem de US\$ 250 milhões de dólares, na sua fase piloto (com duração prevista para 3 anos), proveniente da cooperação internacional dos países do bloco dos 7. O Programa Piloto foi lançado em 1992, sendo que, em 1994, doze projetos tinham sido identificados, e em 1995 os cinco primeiros projetos iniciaram-se, tendo sido finalizado em 1999. Os demais projetos identificados ainda se encontram em fases distintas de preparação. O objetivo do programa piloto é examinar os benefícios ambientais das florestas tropicais do Brasil, consistentes com as metas de desenvolvimento do Brasil, através da implantação de metodologia de desenvolvimento sustentável que contribuirá com a redução contínua do índice de desmatamento.

6 Agenda 21-é um documento resultante da Conferência das Nações Unidas sobre Meio Ambiente e Desenvolvimento de 1992, celebrado no Rio de Janeiro, fruto de um acordo consensual da comunidade internacional acerca da relação homem-natureza diante do paradoxo do crescimento versus desenvolvimento.

Abstract: As part of the process of implementation of Brazilian National Environmental Policy, over the last two decades of the $20^{\text {th }}$ century, decentralization has been adopted in a fragmentary, discontinuous and selective manner. During this period, Brazilian states and municipalities experienced different degrees of decentralization, provoking the need of central government coordination. The institutional vulnerability of several states and municipalities and the limited social capital, are relevant aspects to be considered in the formulation of effective environmental policies. 
Key-words: public policies, environmental management, environmental policy, decentralization

Résumé: La décentralization, en tant que partie du processus d'éxecution de la Politique Nationale de l'Environnement, eut lieu de manière fragmentée, descontinuée et sélective, au long des deux dernières décenies du $20^{\text {ème }}$ siècle. Pendant cette période, les états et municipalités brésiliens ont implanté des différents degrés de décentralization, ce qui a provoqué la necessité d'une coordination par le pouvoir central. La vulnerabilité institutionnelle de plusieurs états et municipalités, liée au faible capital social sont des facteus importants qui doivent être considerés au moment de la formulation de la politique environnementale.

Mots-clés: politique publique, gestion de l'environnement, politique environnementale, décentralisation

\section{Referências bibliográficas}

ABRUCIO, F. L. Os barões da Federação. Lua Nova, v. 33, p. 165-183, 1994.

AGENDA 21 brasileira: ações prioritárias. Comissão de Políticas de Desenvolvimento Sustentável e da Agenda 21 Nacional. 2002. 160p.

BRASIL. Constituição da República Federativa do Brasil. Brasília, DF: Senado Federal, 1988. 292p.

BUARQUE, S. C. Metodologia de planejamento do desenvolvimento local e municipal sustentável: projeto de cooperação técnica INCRA/IICA. Brasília, 1999. 105 p.

BURKI, S. J.; PERRY, G. E.; DILLINGER, W. R. Beyond the center: decentralizing the state. Washington: The World Bank, 1999. 104 p.

CAMARGO, A. Agenda 21 brasileira, descentralização de políticas e democratização do planejamento. In:. FELDMANN, Fábio (Ed.). RIO+10 Brasil: uma década de transformações. Rio de Janeiro: Quickgrafic, 2002.220 p.

FERNANDEZ-VÍTORA, V. C. Los instrumentos de la gestion ambiental en la empresa. Madrid: Ediciones Mundi-Prensa, 1997. 541p.

FERREIRA, P. B. O modelo federativo brasileiro: evolução, o marco da constituição de 1988 e perspectivas. Caderno Debates, Fundação Konrad Adenauer Stiftung, n. 6, p. 7-19, 1995. 
JACOBI, P. Políticas sociais e ampliação da cidadania. Rio de Janeiro: Editora da FGV, 2000. 152 p.

KLIKSBERG, B. ¿Como reformar el estado para enfrentar los desafios socialies del 2000?. In: FORUM GLOBAL ESTADO DEMOCRÁTICO E GOVERNANÇA NO SÉCULO XXI, 2000, Brasília. Comunicação. Brasília, 2000.

MATOS, C.A. La descentralización: una nueva panacea para enfrentar el subdesarrollo regional? In: LAURELLI, E.; ROFMAN, A. (Comp.). Descentralizacion del Estado: requerimentos y políticas in la crisis. Fundación Friedrich Ebert, Ediciones CEUR, 1989. p. 337-363.

MONTORO, F. Subsidiariedade e fortalecimento do poder local. Caderno Debates, Fundação Konrad Adenauer Stiftung, n. 6, p. 58-59, 1995.

PEREIRA, L.C.B. Reforma do Estado para a cidadania: a reforma gerencial brasileira na perspectiva internacional. São Paulo: Ed. 34, Brasília: ENAP, 1998. 368 p.

PUTNAM, R. D. Comunidade e democracia: a experiência da Itália moderna. Rio de Janeiro: Ed. Fundação Getúlio Vargas, 1996. 260 p.

SAYAGO, D. A. V. A invenção burocrática da participação: discursos e práticas no Ceará. Brasília, 2000. 210 p. Tese (Doutorado) Departamento de Sociologia da Universidade de Brasília.

SCARDUA, F. P. Governabilidade e descentralização da gestão ambiental no Brasil. Brasília. 2003. 234 p. Tese (Doutorado) - Centro de Desenvolvimento Sustentável da Universidade de Brasília.

SILVA, P. L. B. Descentralização de políticas sociais: marco teórico e experiências internacional e brasileira. In: REIS VELLOSO, João Paulo dos; ALBUQUERQUE, Roberto Cavalcanti de; KOOP, Joachim (Coords.). Políticas sociais no Brasil: descentralização, eficiência e equidade. Rio de Janeiro: Inae, Ildes, 1995. 236 p.

SILVA, P. L. B.; COSTA, V. L. C. Descentralização e crise da federação. In: AFFONSO, Rui de Brito Álvares; SILVA, Pedro Luiz Barros (Org.). A federação em perspectiva: ensaios selecionados. São Paulo: FUNDAP, 1995. $515 \mathrm{p}$.

SOUZA, C. M. de. Democracia, participação social e funcionamento das instituições: situação e perspectivas da federalização do desenvolvimento. Revista de Administração Pública, Rio de Janeiro, v. 26, n. 3, p.15-35, 1992. 